\title{
Mechanism Research on the Improvement of Bearing Capacity of Single Pile by Pile-base Post Grouting Technique and Estimation of Bearing Capacity
}

\section{Feng Zhao}

School of Construction Engineering, Xi'an University of Science and Technology, Xi'an, Shaanxi, China

$X i$ 'an Research Institute of China Coal Technology and Engineering Group Corp, Xi'an, Shaanxi, China

\begin{abstract}
The slurry wall bored grouting has some defects. The pile-base post grouting technique can efficiently make up these defects and greatly improve the bearing capacity. Based on the pile-base post grouting technique and its process analysis, this paper carries out a detailed analysis about the improvement of mechanism of bearing capacity and mechanism of spherical expansion by the use of pile-base post grouting technique, as well as the estimation method of the bearing capacity of pile-base post grouting pile, which has a certain reference value for theoretical research and technical application of the technique.
\end{abstract}

Keywords: pile-base post grouting; mechanism of action; calculation of bearing capacity

\section{INTRODUCTION}

The pile-base post grouting technique has been widely used for bored pile, especially for large-diameter bored pile, and its effect has been verified by a lot of projects. The development of pile-base post grouting technique has been mature. Currently, there are many kinds of pile-base grouting devices. The principle of construction control is reasonable, and the construction success rate is high. The pile-base post grouting technique has been widely used in pile base engineering of industrial and civil buildings and major bridges $[1-3]$. The bearing capacity of pile-base post grouting should be regarded as guidance for the construction designers and pile-base testers. It is evident for post grouting to improve the calculation of the bearing capacity of pile-base. The pile-base post grouting technique is a technique with the theory lagging behind practice, which is established in the specific engineering design and construction ${ }^{[4-6]}$

The bored pile post grouting technique is a kind of scientific and advanced technical method ${ }^{[7-9]}$ to greatly improve the bearing capacity of the pile and reduce the settlement amount through elimination of the defects on the traditional construction technique of cast-in-place pile, which solidifies soil within a certain range of sediment at the bottom of hole, mud cake at the pile side, pile base and pile side through grouting pipes by the use of high-pressure grouting pump to infuse grout with main agent of cement after the grouting pipes and grouting equipment are embedded in the pile base in the pile formation and the concrete strength of the pile reaching $50 \%$ to $75 \%$.

The technique is applicable to slurry wall drilling, digging, boring cast-in-place pile, drilling and digging cast-in-place pile and other pile-base projects. The post grouting technique has been widely used in $\mathrm{Eu}-$ rope. In recent years, such technique ${ }^{[10-12]}$ is used to improve the bearing capacity of bored pile and reduce sedimentation at pile base of China's high-rise buildings and bridge engineering, such as Yellow River Bridge II, Donghai Bridge, Runyang Bridge, Sutong Bridge and Hangzhou Bay Bridge and so on.

\section{INFLUENCE FACTORS OF BEARING CA-} PACITY OF BORED PILE

The bored pile technique is a practical engineering technique. There are many influence factors of bearing capacity, which are mainly in the following areas:

1. Strength, deformation nature and stress change for pile body to access soil layer.

2. Strength and deformation nature of bearing course at pile end.

3. Geometrical characteristic of pile body and pile base.

4. Material strength of pile body.

5. Pile-forming method.

In terms of the characteristics of bored pile, it belongs to underground concealed project with more construction processes and closely interrelated construction procedures and without pause for a long time. The construction process of the main procedures is underground or underwater, and it is inconvenient to supervise. In addition, it is also restricted by air temperature, weather, traffic, water, electricity, environment, equipment, materials and other factors, and it fails to be accurately predicted. They are prone to have quality defects in pile necking, mud mixture, pile breaking, over-thick sediment piles and other forms, affecting the integrity of the pile body and the bearing 


\section{MATEC Web of Conferences}

capacity of single pile, especially the slurry wall cast-in-place pile. The over-large consistency may form "mud cake" on the surface of pile side to greatly reduce the frictional resistance, while the over-thick sediment at the bottom of hole will obviously decrease the end resistance ${ }^{[13]}$

How to improve the side resistance and end resistance of bored pile is a research subject urgently required to be addressed in the engineering practice. The pile end and pile side post grouting technique is one of effective measures to improve the bearing capacity of cast-in-place pile. This paper focuses on illustration of the mechanism, technique and application effect of bored pile-base post grouting at medium-coarse sand layer of the bearing course at pile end combined with engineering practice. As we all know, in the bored pile construction at medium-coarse sand layer, there are difficulties in cleaning slag and reduction of bearing capacity at pile end by disturbance of medium-coarse sand layer. The pile-base post grouting technique effectively reinforces the medium-coarse sand layer, thereby improving the bearing capacity of pile. Meanwhile, it also greatly reduces the deformation of single pile and the differential settlement of pile groups due to reinforcement of pile end and surrounding soil.

This paper proposes a principle of design calculation through analysis about influence factors of bearing capacity of bored pile and the mechanism of improving the bearing capacity of single pile by bored pile post grouting.

\section{OVERVIEW OF PILE-BASE POST GROUTING TECHNIQUE AND TECHNIQUE CLASSIFI- CATION}

\subsection{Overview of pile-base post grouting technique}

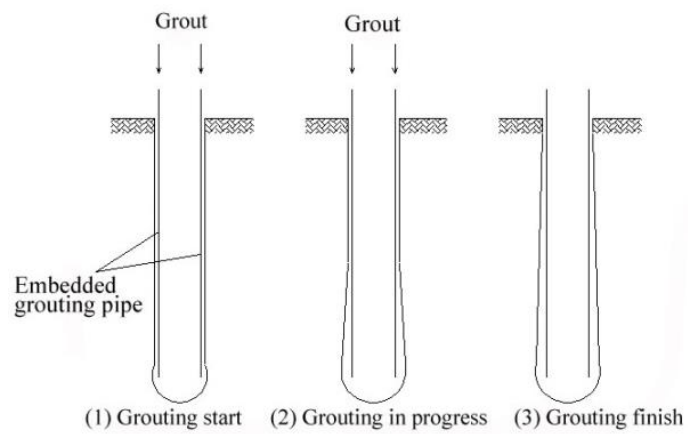

Figure 1. Schematic diagram of pile-base post grouting effect

The pile-base post grouting refers to a project's technical measure that can improve the resistance at pile end and pile side to different degrees, reduce pile sedimentation and significantly improve the bearing capacity of pile through physical and mechanical properties' changes of soil at pile end and surrounding pile side by individual and combined action of solidi- fied grout (such as neat cement slurry, cement mortar, cement paste with admixture, chemical grout and so on) in penetration, filling, replacement, cleaving, consolidation, solidification and other physical or chemical forms through the grouting pipe embedded in the pile body and pressing into the pile end with a certain pressure and an enlarged head at pile base after formation of bored pile. Schematic diagram of pile-base post grouting effect is shown in Figure 1.

\subsection{Technique classification}

Based on the grouting technique, pile end pressure grouting can be divided into two categories: the open grouting and the closed grouting.

The open grouting means that the grout is directly injected into pile end through embedded grouting pipe, and respectively mixed with sediment at pile base and surrounding soil at pile end, so as to form an effect of the composite foundation at pile end; The closed grouting means that the grout is injected into a prefabricated cavity with a good elasticity, and the elastic cavity will gradually swell and expand with the increase of grouting pressure and grouting amount, forming grout bubble in a lower soil layer at pile end, and the generation and gradual expansion of the grout bubble will be bound to produce a compaction effect on the soil layer at pile end ${ }^{[14-16]}$

Obviously, the growing rate of bearing capacity of single pile is relatively stable to use the closed grouting. Especially when the pile end is a sand layer, the effect is better. However, the construction process of closed grouting is more complicated, while the improvement of bearing capacity of open grouting is inferior to that of the former, but its construction process is relatively simple, so it is widely-used.

The bored pile-base post grouting technique herein is an open grouting technique of the embedded grouting pipe on pile body.

\section{MECHANISM OF IMPROVING BEARING CAPACITY BY PILE-BASE POST GROUTING}

1) The grout infiltration rate of grouting is high in bearing course at pile end of the coarse-grained soils (medium sand with a greater porosity, coarse sand, pebble, gravel). The grout can greatly improve the disturbance of the bearing course and strength and deformation modulus of the bearing course that mainly through penetration, part of compaction, filling and consolidation effects, and form an enlarged head to increase the stressed area of pile end and improve the resistance of pile end.

In order to implement the permeability grouting, we assume that the stratum structure is substantially free of disturbance and destruction, and can overcome various obstacles of grout flow and penetrate into holes or fractures in the stratum under grouting pressure. The holes should be filled by penetration and filling methods. After the solidification of grout, soil 
particles are bonded together to form cement-soil stone body, which can greatly improve the disturbance of the bearing course and strength and deformation modulus of the bearing course, and form an enlarged head to increase stressed area of pile end. Thus the growing rate of bearing capacity is large.

Influence factors of grout diffusion range are holes or fractures in the stratum (or permeability coefficient), grout viscosity, grouting pressure and grouting time and so on.

2) The grout infiltration rate of grouting is low in bearing course at pile end of the fine-grained soils (cohesive soil, silty soil, silt, fine sand and so on), thus achieving the fracture grouting. The so-called fracture grouting means that under the grouting pressure, the grout overcomes the initial stress and tensile strength of the stratum, causing destruction and disturbance of soil structure, and making it fracture along the plane perpendicular to the stress, so that the original fractures or holes in the stratum open to form new fractures or holes, and the grout permeates into the stratum along the fracture vein, so the groutability and diffusion length of the grout increase. Under the state of fracture grouting, the failure in the increase of bearing capacity of grouting pile at pile end is due to the existence of fracture grout vein. The single medium of soil body is segmented and reinforced by mesh stone body as composite soil body, so as to improve the density of pile end soil body and effectively transfer and share the load, thereby improving the resistance at pile end ${ }^{[17-18]}$.

With the comparison of grout infiltration rate, the rate of fracture grouting mode is smaller than that of permeability grouting. Therefore, the growing rate of ultimate bearing capacity of pile end grouting pile of the former is much smaller than that of the latter.

3) The pile end sediment and injected grout has physical and chemical reaction and solidification, condensing into a stone body with a new structure, high strength, and stable chemical property, so as to enhance the resistance at pile end.

4) With the increase of grouting amount and grouting pressure, the cement grout continuously penetrates into the bearing course at pile end due to immersion by mud and becoming soft, thus forming aploid at pile end. When the aploid enlarges continuously, the infiltration capacity is restricted by surrounding dense soil, so the pressure continues to rise. The pressure increases play a role of compaction in the bearing course at pile end, thus improving the bearing capacity of pile end soil body. Meanwhile, the aploid is formed at pile end, so the bearing area at pile end increases, and it is equivalent to expanding base for the bored pile, thereby increasing the resistance of slurry wall bored pile at pile end.

5) When grouting in the bearing course at pile end of weathered bedrock with the medium or above impermeability, in case of not enough grouting pressure, due to the constraints of surrounding rock, the pressure grout can only be penetrated or filled in sediment, forming grout bubble to extrude surrounding sediment particles, so that the mud filling among sediments produces dehydration and consolidation; in case of enough grouting pressure, it will produce fracture grouting and compaction effects.

6) When the grouting pressure increases and the grouting amount continuously increases, the grout injected into the pile end may penetrate under pressure along the mud cake among pile soil within a certain height range above the pile end, reinforce the mud cake, fill in gap of the pile body and soil body around pile, and penetrate into a certain width of soil layer around pile. After solidification of grout, a wider range of soil body around pile is mobilized to participate in the pile bearing, so as to increase the pile side friction.

7) For pressure grouting at pile end, when the infiltration capacity at pile end is restricted, the grout pressure of sploid will increase continuously. Under the effect of high-pressure liquid, it may impose upward reverse prestress on the pile end face, and slightly lift up the pile body. When the slurry wall bored pile bears downward vertical load, the reverse prestress will bear partial load, thereby increasing the bearing capacity of pile end.

8) Under the effect of grouting pressure, the compressive deformation at pile end is partially completed ahead of schedule during the construction period, so as to reduce the vertical compressive deformation in the later period of use.

\section{CALCULATION OF SPHERICAL EXPANSION THEORY OF PILE END POST GROUTING}

The spherical expansion theory of pile end post grouting is used for interpretation of representative theory of permeability grouting in the foundation of above the medium sand. The calculation model of spherical expansion theory is shown in Figure 2. The calculation is used to assume:

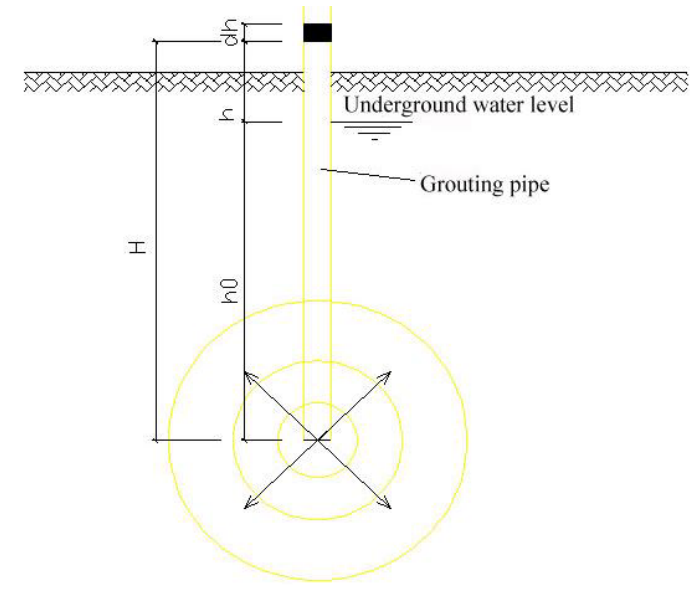

Figure 2. Schematic diagram of grout spherical expansion at the bottom of grouting pipe 


\section{MATEC Web of Conferences}

(1) The grouting sand is homogeneous and homodromous.

(2) The grout is Newtonian fluid, which is generally in line with Newton's law of friction, that is, the linear relationship between the shear stress and the shear deformation speed is called Newtonian fluid.

(3) The grout is injected into foundation soil from the bottom of grouting pipe.

(4) The grout presents a spherical expansion in the stratum.

The grout expansion radius at pile end can be calculated by such assumptions. In the process of grouting, assuming that the grout infiltration is in line with Darcy's Law:

$Q=k g i A t=4 \pi k g i r^{3} t$

$i=-\frac{d h}{d r}$

Substitute into (1): $Q=-4 \frac{k}{\beta} \pi r^{2} t \frac{d h}{d r}$

Through the above integration, $\frac{Q \beta}{4 \pi k t r}=h+C$

When $\mathrm{r}=\mathrm{r}_{0}, \mathrm{~h}=\mathrm{h}_{0}$

$\mathrm{r}=\mathrm{r}_{1}, \mathrm{~h}=\mathrm{h}_{1}$

Substitute into (2) Formula,

$$
\mathrm{h}_{0}-\mathrm{h}_{1}=\frac{Q \beta}{4 \pi k t}\left(\frac{1}{r_{0}}-\frac{1}{r_{1}}\right)
$$

Assuming that the filling rate of grout is $\alpha$, then

$Q=\frac{4}{3} \pi d r_{1}^{3} n$

Substitute Formula (4) into Formula (3):

$\mathrm{h}_{0}-\mathrm{h}_{1}=\frac{r_{1}^{3} n \alpha \beta}{3 k t}\left(\frac{1}{r_{0}}-\frac{1}{r_{1}}\right)$

So: $\Delta h=\frac{r_{1}^{3} n \alpha \beta}{3 k t}\left(\frac{1}{r_{0}}-\frac{1}{r_{1}}\right)$

When $\mathrm{r}_{0} \gg \mathrm{r}_{1}$, so $\mathrm{r}_{1}=\sqrt{\frac{3 k t r_{0} \Delta h}{\alpha \pi \beta}}$

Where:

$\mathrm{k}$ is the permeability coefficient of soil and assume that the grouting process is constant;
$\mathrm{Q}$ is the grouting amount;

$\mathrm{kg}$ is the permeability coefficient of grout in the stratum, $\mathrm{kg}=\mathrm{k} / \beta$;

$\beta$ is the ratio of grout viscosity to water viscosity. Assume that the grouting process is constant;

$\mathrm{A}$ is the permeability area;

$r_{1}$ is the radius of grout diffuser;

$h_{1}$ is the water pressure head at the edge of grout diffuser;

$\mathrm{h}_{0}$ is the grout pressure head at the grouting nozzle;

$\mathrm{H}$ is a sum of underground water head at the grouting nozzle and grouting pressure;

$\mathrm{r}_{0}$ is the radius of grouting pipe;

$t$ is the grouting time;

$\mathrm{n}$ is the soil porosity.

As can be seen from the Formula (7), the solid size increases with the increase of the permeability coefficient of soil $(\mathrm{k})$ and the grouting head difference at the exit $(\Delta \mathrm{h})$, and it decreases with the increase of filling rate $(\alpha)$, soil porosity (n) and grout viscosity. In addition, the permeability coefficient of soil decreases with the increase of filling rate $(\alpha)$. The compaction and fracture grouting should also involve in soil strength, stress-strain relationship and changes in the grouting process ${ }^{[19-25]}$.

Therefore, the reinforcement range could not expand with the increase of time, which only indicates that the achievement of a certain reinforcement range requires adequate grouting time.

\section{ESTIMATION METHOD OF BEARING CA- PACITY OF PILE END GROUTING PILE}

\subsection{Problems in specifications}

According to the specifications of Article 5.2.8 and Article5.2.9 in Technical Specifications for Pile Foundation (JGJ94-94), the standard value of vertical ultimate bearing capacity of single pile of slurry wall bored pile can be calculated by the Formula (5.2.8). Where: $\mathrm{q}_{\text {sik }}$ takes the value according to Table 5.2.8-1 in the specification; $\mathrm{q}_{\mathrm{pk}}$ takes the value according to Table 5.2.8-1 in the specification. When the pile diameter $\mathrm{d} \geq 800 \mathrm{~mm}$, there is a need to introduce two large-diameter piles side resistance and coefficient of pile end size effect of $\psi_{\mathrm{si}}$ and $\psi_{\mathrm{p}}$, and take value according to 5.2.9-2 in the specification.

$$
Q_{u k}=Q_{s k}+Q_{p k}=u \sum \psi_{s i} q_{s i k} l_{s i}+\psi_{p} q_{p k} A_{p}
$$

This method mainly considers the improvement of vertical bearing capacity of single pile, which is mainly reflected in the end bearing. The first is the increase of intensity of pile end soil and elimination of sediment, and the second is expansion of stressed area at pile end without considering the increase of side resistance. Therefore, this method considers that the pile diameter after grouting should be calculated by the pile diameter designed originally. $\mathrm{q}_{\mathrm{sik}}$ takes value according to Table 5.2.8-1 in JGJ94-94, while the end 
EMME 2015

Table 1. Composite value $\left(\mathrm{q}_{\mathrm{pk}}\right)$ of ultimate end resistance of pile end grouting pile

\begin{tabular}{|c|c|c|c|c|c|c|}
\hline \multirow{2}{*}{ Name of soil } & \multirow{2}{*}{ Status of soil } & \multicolumn{4}{|c|}{ Buried depth of slurry wall bored pile $(\mathrm{h} / \mathrm{m})$} & \multirow{2}{*}{$\begin{array}{l}\text { Grouting } \\
\text { times }\end{array}$} \\
\hline & & $\mathrm{h} \leq 9$ & $9<\mathrm{h} \leq 16$ & $16<\mathrm{h} \leq 30$ & $\mathrm{~h}>30$ & \\
\hline Sandy sticky clay & $0.25<\mathrm{I}_{\mathrm{L}} \leq 0.5$ & $1200 \sim 1800$ & $1800 \sim 2400$ & $2400 \sim 2900$ & $2900 \sim 3500$ & 1 \\
\hline $\begin{array}{l}\text { Residual soil, } \\
\text { strong weathered rock } \\
\text { ridge }\end{array}$ & $0<\mathrm{I}_{\mathrm{L}} \leq 0.25$ & $2200 \sim 2900$ & $2900 \sim 3700$ & $3700 \sim 4500$ & $4500 \sim 5300$ & 1 \\
\hline Silty soil & $\begin{array}{l}0<\mathrm{I}_{\mathrm{L}} \leq 0.25 \\
\mathrm{e} \leq 0.75\end{array}$ & $\begin{array}{l}650 \sim 1300 \\
1200 \sim 1800\end{array}$ & $\begin{array}{l}1300 \sim 1600 \\
1800 \sim 2400\end{array}$ & $\begin{array}{l}1600 \sim 2000 \\
2400 \sim 2800\end{array}$ & $\begin{array}{l}2000 \sim 2550 \\
2800 \sim 3500\end{array}$ & $\begin{array}{l}1 \\
1\end{array}$ \\
\hline Silt & $\begin{array}{l}\text { Slightly dense, medi- } \\
\text { um dense, dense }\end{array}$ & $\begin{array}{l}650 \sim 1300 \\
1200 \sim 1800 \\
\end{array}$ & $\begin{array}{l}1300 \sim 1700 \\
1800 \sim 2550 \\
\end{array}$ & $\begin{array}{l}1700 \sim 2000 \\
2550 \sim 3000 \\
\end{array}$ & $\begin{array}{l}2000 \sim 2400 \\
3000 \sim 3800 \\
\end{array}$ & $\begin{array}{l}1 \\
1 \\
\end{array}$ \\
\hline $\begin{array}{l}\text { Fine sand, medium } \\
\text { sand, coarse sand }\end{array}$ & Medium dense, dense & $\begin{array}{l}2000 \sim 3300 \\
3000 \sim 5000 \\
5000 \sim 7000\end{array}$ & $\begin{array}{l}3300 \sim 4000 \\
5000 \sim 6000 \\
7000 \sim 8000\end{array}$ & $\begin{array}{l}4000 \sim 4700 \\
6000 \sim 6500 \\
8000 \sim 9000\end{array}$ & $\begin{array}{l}4700 \sim 5500 \\
6500 \sim 7000 \\
8500 \sim 9000\end{array}$ & $\begin{array}{l}2 \\
2 \\
2\end{array}$ \\
\hline $\begin{array}{l}\text { Gravel sand, dust, } \\
\text { pebble, gravel, scree, } \\
\text { strong weathered rock } \\
\text { ridge, gravelly soil }\end{array}$ & Medium dense, dense & $\begin{array}{l}6000 \sim 9000 \\
7000 \sim 10000 \\
8000 \sim 11000\end{array}$ & & & & $\begin{array}{l}2 \\
2 \\
2\end{array}$ \\
\hline
\end{tabular}

resistance $\mathrm{q}_{\mathrm{pk}}$ adopts a composite value to adjust the vertical bearing capacity of single pile.

\subsection{Calculation based on the adjustment value of side resistance after grouting}

To adjust the standard value of total ultimate side resistance of pile end grouting pile:

$\mathrm{q}_{\mathrm{pk}}$ takes value according to Table $2 . \mathrm{q}_{\mathrm{pk}}$ refers to Table 2 . Table 2 is a composite value of $\mathrm{q}_{\mathrm{pk}}$ after adjustment according to the test results. For a large-diameter pile $(\mathrm{d} \geq 800 \mathrm{~mm})$, the size effect coefficient takes value according to Table 5.2.9-2 in JGJ94-94.

\subsection{Calculaiton formula of ultimate bearing capacity of single post grouting pile}

Consider the problem of diameter expansion of grouting

1) Calculation of pile diameter (r') at the expansion of pile body

$$
\mathrm{r}^{\prime}=\left\{\left(\mathrm{H}_{\text {grout }} /\left(\rho_{\text {grout }} \cdot \mathrm{C}_{\text {grout }}\right)\right) /(\mathrm{L} \cdot \pi)+\mathrm{r}^{2}\right\}^{1 / 2}
$$

Where:

$\mathrm{H}_{\text {grout }}$ is the grouting amount;

$\rho_{\text {grout }}$ is the grout density;

$\mathrm{C}$ grout is the grout stone rate;

$\mathrm{L}$ is the pile length at the expansion of pile (a sum of pile length of non-clay layer);

$r$ is the radius of bored pile (pile radius of non-expansion place);

2) Standard value of vertical ultimate bearing capacity of single post grouting pile $\left(\mathrm{Q}_{\mathrm{uk}}\right)$ :

$Q_{u k}=Q_{s k}+Q_{p k}^{\prime}+Q_{p k}=u \sum q_{s i k} l_{i}+q_{p j k}^{\prime} A_{p j}^{\prime}+q_{p k} A_{p}$

Where: $Q_{\mathrm{sk}}$ is the standard value of total ultimate bearing capacity of pile side;

$\mathrm{Q}_{\mathrm{pk}}$ is the standard value of total ultimate side resistance at the place of expansion of pile;
$\mathrm{Q}_{\mathrm{pk}}$ is the standard value of total ultimate side resistance at pile end;

$\mathrm{u}$ is the perimeter of pile body, and the diameter expansion is $2 \pi r^{\prime} \cdot l_{j}$, the non-diameter-expansion is $2 \pi r \cdot l_{i}$

$\mathrm{q}_{\mathrm{sik}}$ is the standard value of ultimate side resistance at the $i^{\text {th }}$ layer of soil at pile side (take value according to the underwater bored pile in Table 5.2.8-1 of the Specification);

$l_{i}$ is the thickness at the $i^{\text {th }}$ layer of soil;

$\mathrm{q}_{\mathrm{pjk}}{ }^{\prime}$ is the standard value of ultimate side resistance at the $\mathrm{j}^{\text {th }}$ expansion of pile body (take value according to the operating bored pile in Table 5.2.8-1 of the Specification);

$A_{p j}^{\prime}$ is the expansion area at the $j^{\text {th }}$ expansion of pile body, $\mathrm{A}_{\mathrm{pj}}^{\prime}=\pi \cdot\left(\mathrm{r}^{2}-\mathrm{r}^{2}\right)$;

$\mathrm{q}_{\mathrm{pk}}$ is the standard value of ultimate side resistance at pile end (take value according to operating grouting pile in Table 5.2.8-1 of the Specification);

$A_{p}$ is the sectional area at pile end.

\section{CONCLUSION}

1) Through pile-base post grouting treatment, the slurry wall bored pile can effectively deal with sediment at pile base, eliminate hidden dangers at pile base, reduce the discreteness of vertical bearing capacity of the pile foundation and differential settlement, so as to ensure the quality stability of the pile foundation.

2) Through pile-base post grouting treatment, the vertical bearing capacity of single pile can be calculated by the numerical values provided herein, but it should be determined through engineering static load test. Due to the complexity of pile end pressure grouting, calculation of pile end pressure grouting pile is not mature enough. The current calculation method of the bearing capacity of grouting pile is only applied to short small and medium diameter pile in the construc- 


\section{MATEC Web of Conferences}

tion sector

3) After the pile end grouting, the pile side resistance and pile end resistance has been improved to varying degrees. How to analyze and summarize the distribution rules of bearing characteristics of bored pile after grouting and pile side friction and end resistance through a large number of data on the static load test and stress-strain test of test pile should be our future research directions.

4) The impact of pile end post grouting on the pile group effect and how to consider the pile group effect in design requires an in-depth research and analysis.

\section{REFERENCES}

[1] Zhang Chunfeng, Wang Xiao, \& Yao Wenjuan. 2015. Research on post grouting super-long pile test and ultimate bearing capacity. Construction Technique, 07: $63-67+71$.

[2] Deng Xianghui, Zhang Yongjie, \& Fang Haibo. 2015. Analysis and experimental research on the bearing capacity of post grouting bored pile. Journal of Architecture Science and Engineering, 02: 58-64

[3] Wang Gang, \& Li A'lei. 2014. Experimental research on the bearing capacity of cast-in-place pile post grouting. Highway and Transportation Research (Applied Technique), 06: 262-264.

[4] Wang Bin, Zhu Jintai, \& Xu Zhongwen. 2013. Application of slurry wall bored pile post grouting technique. Building Technique Development, 02: 46 - $47+60$.

[5] Wang Zhongfu, Liu Handong, He Siming, \& Huang Zhiquan. 2013. Experimental research on the load of vertical bearing characteristics of post grouting super-long cast-in-place pile. Journal of Underground Space and Engineering, 02: $253-257+262$.

[6] Tian Xuefei, Lu Haijun, Yan Jingxia, Chu Chengfu, Lu Lihao, \& Dong Mansheng. 2013. Comparative research on the calculation method of bearing capacity of post grouting pile foundation. Journal of Geotechnical Engineering, S1: 372-377.

[7] Wu Yizhang. 2013. Experimental research on the bearing capacity of post grouting cast-in-place piles in silt region. Building Science, 07: 66-70.

[8] Liu Jinli, \& Zhu Jingcheng. 1996. Technique and its application of slurry wall cast-in-place pile post grouting, Building Foundation Institute of China Academy of Building Research.

[9] Li Shijing, Liu Xiaomin, \& Yang Jianlin, 1990.Bored pile construction technique, Beijing, Geological Publishing House

[10]Chen Xiaoming, \& Lin Shan. 1999. Post grouting technique of slurry wall cast-in-place pile-base and estimation method of vertical bearing capacity of single pile, Exploration Engineering, (3).
[11] Ye Shulin, et al. 1998. Foundation treatment manual, Beijing, China building industry press.

[12] Wang Zhihui, Liu Bin, \& Zhuang PingHui. 2002. Bearing character test of large-diameter pile-end pressure grouting pile. Journal of Northeastern University, (02).

[13] Hu Qingli, \& Zhang Kexu. 2002, Finite element analysis of pile-base grouting pile under axial load effect. Journal of Harbin Building University, (01).

[14]Huang Shenggen, Zhang Xiaohui, \& Cao Hui. 2004 Research on the load transfer mechanism of post grouting bored piles. Rock and Soil Mechanics, (02).

[15]Feng Dingbo. 2009. Analysis of the mechanism of pile-end post grouting on the improvement of bearing capacity of bored piles. Chinese and Overseas Architecture, (6).

[16] Wang Baode, 2005. Application of pile-base post grouting technique. Tianjin Construction Science and Technique, (01)

[17]Liu Tao, \& Sun Xuexian. 2008. Discussion of the impact of side resistance changes of pile-base post grouting bored piles on vertical bearing capacity. Communications Standardization, (05).

[18]Liu Tao, \& Sun Xuexian. 2008. Discussion of the impact of side resistance changes of pile-base post grouting bored piles on vertical bearing capacity. Communications Standardization, (05).

[19] Li Wenzhou. 2012. Calculation of bearing capacity of static-pressure prestressed pipe pile post grouting in silt region. Construction Technique, 05: 95-99.

[20]Jiang Yunfeng, \& Wang Xinyang. 2012. Discussion of cast-in-place pile post grouting technique. Highway and Transportation Research (Applied Technique), 11 264-266.

[21]Yu Zhihua, Liu Yanyan, Song Jian, Rong Xiaoyang, \& Cui Wenyan. 2011. Bored pile end post grouting technique and engineering application. Journal of Water Resources and Architectural Engineering, 03: 40-43.

[22]Xu Jun. 2011. Application of bored pile-base post grouting technique in high-rise buildings with soft foundation. Journal of Ningbo University (Science and Engineering), 03: 67-70.

[23] Bu Anhui. 2011. Application of pile-base post grouting technique in pile-base construction of high-rise buildings. Chinese and Overseas Architecture, 06: 150-151.

[24]Chu Chengfu, Li Xiaochun, Lu Lihao, \& Xi Peisheng. 2011. Research on bearing capacity of pile-base grouting under super-long and large-diameter bored pile in non-cohesive land area. Journal of Geotechnical Engineering, S2: 388 -391.

[25]Liu Dapeng, Wang Guihe, \& Wei Liangliang. 2011. Application of post grouting spinning bored pile in Tangshan area. Construction Technique, S2: 69-71. 